\title{
OPTIMISTIC ENTREPRENEURS AND NEW PRODUCT INTRODUCTIONS IN HIGH TECHNOLOGY INDUSTRIES
}

\author{
R. ISIL YAVUZ \\ Faculty of Business \\ Özyeğin University \\ Istanbul 34794, Turkey \\ E-mail: isil.yavuz@,ozyegin.edu.tr \\ DEV K. DUTTA \\ University of New Hampshire, Durham, USA \\ MEHMET A. SOYTAS \\ Özyeğin University, İstanbul, Turkey
}

\begin{abstract}
This study examines how the relationship between past performance and new product introductions is influenced by entrepreneurial optimism. Our results show that the rate of new product introductions is highest in new ventures founded by optimistic entrepreneurs where the new ventures have shown low prior performance relative to their aspirations.
\end{abstract}

\section{INTRODUCTION}

Researchers attempting to understand risky organizational actions such as new product introductions often draw insights from the behavioral theory of the firm (Cyert \& March, 1963). According to the behavioral theory, firms performing below aspirations tend to take risks and initiate strategic change, in order to improve performance to a satisfactory level. On the other hand, firms operating at or above aspirations tend to maintain the status quo (Cyert \& March, 1963, Bromiley, 1991, Chen \& Miller, 2007, Greve, 2010). However, most insights on the effect of past performance on risky organizational actions such as new product introductions have been generated in the context of large, well-established public companies. These companies tend to be resource rich and are thus in an advantageous position with regard to investing in new products as performance falls short of aspiration levels. This is because having a performance decline during a period does not necessarily mean resource shortage (Greve, 2003; Chen \& Miller, 2007). But this is not the case with resource constrained new ventures. Further, the impact of deviations in performance on new product introduction decisions in young, entrepreneurial ventures remains understudied.

Moreover, prior research has confirmed that in new firms founder psychological characteristics have a significant impact on the venture's emerging trajectory (Protogerou, Caloghirou \& Vonortas, 2017). An essential trait of entrepreneurs is their dispositional optimism, or the proclivity to achieve positive outcomes even when such expectations do not have a rational justification (Hmielski \& Baron, 2009). Prior research has documented that entrepreneurial optimism is a positive motivating force that brings about change (Dushnitsky, 2010). We argue that exploring performance feedback in conjunction with founder optimism will yield a more nuanced understanding of the nature of new product introductions in new ventures, 
based on performance feedback. Accordingly, in this study we examine whether and how founder dispositional optimism - an important psychological characteristic - interacts with performance feedback to affect new product introductions by high technology new ventures.

Our supposition is that entrepreneurial optimism significantly affects the relationship between past performance and new product introductions such that when the performance is below aspirations, it is the new ventures with optimistic founders that are going to perceive past performance as a warning for an urgent need for change and take risky actions to restore declining performance with the positive expectation that new product introductions will be successful. New ventures with less optimistic founders, on the other hand, will perceive low performance as a threat to their very survival and will not take any additional risks by introducing new products with the expectation that new initiatives are not going to be successful.

We test our hypotheses by examining 344 high technology new ventures. Our data came from the Kauffman Firm Survey (KFS) - a large panel dataset of new ventures in the US. Since we examine a large number of new ventures over time, this also helps us address the issue of reverse causation and survivor bias. While prior studies typically measured performance feedback by using objective measures, we use both objective and subjective measures. By addressing these empirical issues, we believe our study is advancement in the quantitative empirical examination of behavioral theory of the firm as applied in the context of new ventures.

The study's principal contribution is to bridge an important theoretical gap in behavioral theory by linking it to the context of entrepreneurial ventures, and in the high-tech business environment. By taking into account the distinctive nature of startup companies, our research examines how response to performance feedback in new ventures operating with limited resources is contingent on the personal characteristics of their founders. We theorized for and find evidence that while there is no significant main effect of past performance on new product introductions, there is a significant interaction effect between founders' optimism and performance feedback on new product introductions. Specifically, new ventures with more optimistic founders are more likely to introduce new products when performance is below aspirations compared to their less optimistic counterparts.

\section{THEORY AND HYPOTHESES}

\section{Performance Feedback and New Product Introductions}

One of the fundamental tenets of BTOF is that when faced with imperfect information and in view of their own bounded rationality, decision-makers end up satisficing with regard to performance expectations rather than optimizing on performance targets (Cyert \& March, 1968). Levinthal \& March (1981) suggest the firm's managers follow an adaptive model of decisionmaking, which connects aspirations, actual performance, and adaptation for the future. Decisionmakers set up ex ante organizational performance aspirations. These are compared against actual performance achieved. Depending on the discrepancy between aspiration and performance, decision-makers may go for strategic reorientation and change. In other words, managers look to past performance as a signal of success or failure, in order to determine managerial action (Cyert \& March, 1963; Levinthal \& March, 1981). Low performance relative to aspirations is taken to be a problem. To raise performance above the aspiration level, firms search for alternative solutions, undertaking new strategic initiatives such as new product introductions. High performance relative to aspirations, on the other hand, causes managers to maintain the current 
operations and limit new strategic initiatives (Levinthal \& March, 1981, Greve, 1988, Bromiley, 1991; Chen \& Miller, 2007, Chen, 2008). This leads us to the following hypothesis:

Hypothesis 1a: The probability that an entrepreneurial venture introduces a new product is higher when past performance is below aspirations than when past performance is the same as or above aspirations.

Some entrepreneurship scholars recently highlighted that firm age as well as its size changes the way ventures respond to positive and negative performance feedback (Wennberg, Delmar \& Mckelvie, 2016). These researchers argue that new ventures are very different from well-established companies because not only do they have very limited resources but also they lack prior history and established routines for decision-making. In the early stages of their lifecycle, new ventures engage in bringing in their initial products or services to the market, developing relationships with customers and suppliers, and establishing organizational processes and procedures. Therefore, when surrounded by uncertainty regarding the viability of the venture and the market potential during those initial years, new ventures become especially attentive to emerging performance trends and adjust both their aspiration levels and their preference to take risks (Wennberg, Delmar \& Mckelvie, 2016). According to this group of researchers, when performance falls below the aspiration level, younger ventures are likely to take this initial feedback as an indication of the true potential of the venture, more likely to admit failure and adjust their aspiration downwards, which decrease risk-taking. Moreover, because low performance presents a direct threat to venture survival in the case of new ventures with limited resources, these ventures tend to avoid risky actions such as new product introductions when their performance is below the aspiration level (Wennberg, Delmar \& Mckelvie, 2016). On the other hand, when performance is above the aspiration level, young ventures easily update their aspirations upwards because "positive performance enhance entrepreneurs' beliefs about demand for their products or services and their own abilities, encouraging them to adjust aspiration levels upwards and increase risk taking toward growth (Wennberg, Delmar \& Mckelvie, 2016, pg 413)". Moreover, high performance also provides these ventures with an increased ability to accumulate and attract resources necessary for introducing new products (Bolummole, Calantone, Benedetto, \& Melnyk, 2015). This leads us to the following hypothesis:

Hypothesis $1 b$ : The probability that an entrepreneurial venture introduces a new product is higher when past performance is same as or above aspirations than when the past performance is below aspirations.

\section{The Moderating Effect of Founder Optimism}

Optimism is "...the extent to which people hold generalized favorable expectancies for the future" (Carver, Scheier \& Segerstrom, 2010: 879). As a psychological trait measuring individual differences, optimism has been found to be related to four out of the five major factors of personality: neuroticism, extraversion, agreeableness and conscientiousness (Sharpe, Martin \& Roth, 2011). With regard to the impact of optimism on entrepreneurial performance, results of previous studies remain inconclusive. Some researchers have found optimism to be beneficial in entrepreneurial pursuits (Dawson \& Henley, 2012). This occurs through raising entrepreneurial curiosity (Jeraj, 2014), enabling individuals to increase creative outcomes, based on the 
mediating influences of positive affect and positivity (Rego, Sousa, Marques \& Pina e Cunha, 2012). In turn, optimism has a positive impact on entrepreneurial success (Chen, Liao, Redd \& Wu, 2013). Yet, other authors (e.g. Hmielski \& Baron, 2009) find that in new ventures optimism is negatively related to performance of new ventures, which makes them conclude highly optimistic entrepreneurs tend to misjudge the riskiness associated with their projects (Palich \& Bagby, 1995).

Even though the two views about the potential impact of optimism on venture performance remain irreconcilable, there is no doubt that optimism has a decidedly positive impact on entrepreneurial motivation and action in the face of change. It has been noted that optimism is significantly associated with measures for coping (Anderson, 1996). Aspinwall, Richter \& Hoffman (2001) note, in general optimists are more effective than pessimists at processing negative information, and processing such information more thoroughly and flexibly. The positive affect associated with optimism raises entrepreneurial curiosity (Jeraj, 2014), leading individuals to put more effort on the search process (Papenhausen, 2010), enhancing creative behavior (Rego et al, 2012) when faced with change. Further, Hayward, Shepherd \& Griffin offer the hubris theory of entrepreneurship to suggest that ways in which founders socially construct their confidence levels does have an impact on the manner in which they interpret information relating to their current and previous ventures, leading them to initiate action. Based on these arguments about the positive role of optimism in spurring entrepreneurial action, we argue that optimistic entrepreneurs will tend to respond to performance shortfalls with continuing efforts to solve problems and introduce new strategic initiatives, to try and improve future performance. In contrast, unoptimistic entrepreneurs will tend to disengage themselves from the issue instead of actively trying to solve the performance problem they are beset with. As such, in our view optimistic entrepreneurs are more likely to respond to failure by initiating new strategic initiatives such as going for new product introductions, with the hope that the new initiatives will succeed and raise future performance. Unoptimistic entrepreneurs, on the other hand, will lose the momentum for action when faced with performance declines. Therefore, we suggest the following hypothesis:

Hypothesis 2: The level of founder optimism moderates the relationship between past performance and new product introductions such that when performance falls short of aspirations, new ventures founded by more optimistic founders are more likely to introduce new products relative to those founded by less optimistic founders.

\section{DATA and METHODS}

\section{Sample}

Firm level data to test the hypotheses come from a secondary data source - the Kaufmann Firm Survey (KFS). The data set consists of an initial and seven follow up surveys (of the same firms) in from 2004 to 2011 done by the Kaufmann Foundation. Because KFS follows the same cohort of firms over time (eight years from 2004 to 2011), it helps us observe past performance during the first four years and observe new product introductions during the next three years. Therefore, in our study, from the 705 high technology firms in the sample in 2004, we limit the data to the set of firms that are present in in 2008, which reduces the sample size to 333 . 
The dependent variable is new product introduction, measured as a discrete variable every year from 2008 to 2011 and coded 1 if the venture introduced at least one new product to the market in that year and 0 otherwise. This operationalization is consistent with prior literature (e.g., Brancati, 2015). A version of this variable captures the number of new products after 2008, and analysis with this measure is used as a robustness check. We measure our independent variable, past performance relative to aspirations, or performance feedback, with the following question: "I would like you to think about how much you expected to your business to grow since the business was started. How much do you think your business met your expectations for growth between when the business started (2004) and 2008'? Would you say your business's growth a) Exceeded, b) Met, or c) Did not meet your expectations? We coded 1 if the answer is "exceeded", or "met", and coded 0 if the answer is "did not meet expectations". Our moderator variable, founder optimism is measured in 2008 as 5-point scale item to the question "In uncertain times, I usually expect the best." We also incorporated a comprehensive set of control variables to account for alternative explanations, including gender, education, the average number of hours the primary founder work for his/her start up, number of owners, number of employees and total assets and whether the industry is technology generating or not. We also used two-digit SIC Industry dummies as control variables in our robustness checks.

\section{RESULTS}

The results show that past performance relative to aspirations does not have a significant main effect on new product introductions, failing to support Hypotheses 1a \& 1b. One main concern with the estimations regarding our first set of hypotheses might be the effect of selection bias on the results. The selection bias arises since our sample consists only of firms who are able to survive the first four years and manage to report their past performance relative to aspirations. These firms may differ in important ways from firms which did not survive. Although we try to include as many relevant variables as possible as controls, differences between these two groups might be due to some unmeasured variables. For example, new firms which have performed superior relative to aspirations may be more likely to survive. To correct for the possible effect of selection bias and check our results validity under selection, we estimated a Heckman selection specification. The mills ratio is not significant in the new product introduction equation and the coefficient of our main variable, performance feedback measure remains still insignificant.

Results show that the moderating variable (performance feedback*founder optimism) significantly affects the relationship between performance feedback and new product introductions, providing support for our second hypothesis, indicating that that the effect of past performance on new product introductions is contingent on the level of founder optimism. To detail the interaction effect, we compared regression coefficients of high performing and low performing new ventures to see if founder optimism influences the probability of new product introductions significantly differently for low performing and high performing new ventures. Our results show that while founder optimism has no significant effect on new product introductions in high performing new ventures, it significantly increases new product introductions in low performing new ventures.

\section{DISCUSSION AND IMPLICATIONS}


We drew on the behavioral theory of the firm to examine the interplay between performance feedback and entrepreneurial optimism leading to new product introductions in high technology new ventures. We had argued that low performance relative to aspirations affect new product introductions (Hypothesis $1 \mathrm{a} \& \mathrm{H} 1 \mathrm{~b}$ ) and entrepreneurial optimism strengthens this relationship (Hypothesis 2). We tested our hypotheses using data from the Kauffman Firm Survey on a cohort of 333 high-tech new ventures founded in the U.S. Our results did not provide empirical support for our first set of hypotheses, but strongly supported our second hypothesis, meaning that low prior performance relative to aspirations significantly increases new product introductions in ventures founded by optimistic entrepreneurs. This is an important finding. It suggests that in high-tech entrepreneurial ventures simply recognizing performance deviations against aspirations by the entrepreneur is not enough, in order to usher in strategic change. What is also required is a high level of optimism on the part of the entrepreneur. New product introduction in high-tech entrepreneurial ventures is fraught with risk and uncertainty (Hora \& Dutta, 2013). As such in the face of a negative consequence such as falling short on aspirations, the entrepreneur definitely needs to be optimistic in order to go ahead with new product introduction, with the hope that this will stem the downward slide in performance vis-àvis initial aspirations and redress the situation through performance improvement in future.

Our study contributes to strategic management and entrepreneurship by beginning to fill an important theoretical gap in BOTF literature, which has focused primarily on the wellestablished companies. By taking into account the distinctive nature of startup companies, we theoretically incorporate and empirically document the role of entrepreneurial optimism in the relationship between past performance and new product introductions. This understanding is important not only because our theoretical knowledge of the behavioral implications of performance feedback in an entrepreneurial setting happens to be very limited, but also because this knowledge is practically important for new ventures operating in dynamic and uncertain environments. In these environments, how entrepreneurs make sense of performance feedback in unique ways and take different strategic actions would be critical in determining differing firm performance (Shane, Locke \& Collins, 2003). Therefore, an implication for future research would be to examine the effects of other entrepreneurial characteristics in the relationship between performance feedback and strategic actions in high-tech new ventures.

Acknowledgement: We greatly acknowledge the support of the Ewing Marion Kauffman Foundation in providing access to the KFS data in the NORC Data Enclave. All errors remain ours.

\section{REFERENCES AVAILABLE FROM AUTHORS}

